\title{
Sterol regulatory element-binding proteins are regulators of the sodium/iodide symporter in mammary epithelial cells
}

\author{
G. Wen, L. I. Pachner, D. K. Gessner, K. Eder, and R. Ringseis ${ }^{1}$ \\ Institute of Animal Nutrition and Nutrition Physiology, Justus-Liebig-Universität Gießen, Heinrich-Buff-Ring 26-32, 35392 Gießen, Germany
}

\begin{abstract}
The sodium/iodide symporter (NIS), which is essential for iodide concentration in the thyroid, is reported to be transcriptionally regulated by sterol regulatory element-binding proteins (SREBP) in rat FRTL-5 thyrocytes. The SREBP are strongly activated after parturition and throughout lactation in the mammary gland of cattle and are important for mammary epithelial cell synthesis of milk lipids. In this study, we tested the hypothesis that the NIS gene is regulated also by SREBP in mammary epithelial cells, in which NIS is functionally expressed during lactation. Regulation of NIS expression and iodide uptake was investigated by means of inhibition, silencing, and overexpression of SREBP and by reporter gene and DNA-binding assays. As a mammary epithelial cell model, the human MCF-7 cell line, a breast adenocarcinoma cell line, which shows inducible expression of NIS by all-trans retinoic acid (ATRA), and unlike bovine mammary epithelial cells, is widely used to investigate the regulation of mammary gland NIS and NIS-specific iodide uptake, was used. Inhibition of SREBP maturation by treatment with 25-hydroxycholesterol $(5 \mu M)$ for $48 \mathrm{~h}$ reduced ATRA $(1 \mu M)$-induced mRNA concentration of NIS and iodide uptake in MCF-7 cells by approximately 20\%. Knockdown of SREBP-1c and SREBP-2 by RNA interference decreased the mRNA and protein concentration of NIS by 30 to $50 \% 48 \mathrm{~h}$ after initiating knockdown, whereas overexpression of nuclear SREBP (nSREBP)-1c and nSREBP-2 increased the expression of NIS in MCF-7 cells by 45 to $60 \%$, respectively, 48 $\mathrm{h}$ after initiating overexpression. Reporter gene experiments with varying length of NIS promoter reporter constructs revealed that the NIS 5 '-flanking region is activated by nSREBP-1c and nSREBP-2 approximately 1.5 - and 4.5-fold, respectively, and activation involves a SREBP-binding motif (SRE) at -38 relative to the transcription start site of the NIS gene. Gel shift assays using oligonucleotides spanning either the wild-
\end{abstract}

Received March 16, 2016.

Accepted July 17, 2016.

${ }^{1}$ Corresponding author: robert.ringseis@ernaehrung.uni-giessen.de type or the mutated SRE at -38 of the NIS 5 '-flanking region showed that in vitro-translated nSREBP-1c and nSREBP-2 bind only the wild-type but not the mutated SRE at -38 of NIS. Collectively, the present results from cell culture experiments with human mammary epithelial MCF-7 cells and from genetic studies show for the first time that the NIS gene and iodide uptake are regulated by SREBP in cultured human mammary epithelial cells. Future studies are necessary to clarify if the regulation of NIS expression and iodide uptake by SREBP also applies to the lactating bovine mammary epithelium.

Key words: sodium/iodide symporter, sterol regulatory element-binding proteins, mammary gland, iodide transport

\section{INTRODUCTION}

The sodium/iodide symporter $\left[\mathrm{Na}^{+} / \mathrm{I}^{-}\right.$symporter (NIS)] is an integral glycoprotein in the basolateral membrane mediating the efficient uptake of iodide from the bloodstream into cells. The NIS is best known for its essential role in the concentration of iodide in the thyroid, an important prerequisite for the synthesis of iodine-containing thyroid hormones in the thyroid (Carrasco, 1993). The NIS gene expression in the thyroid is principally regulated by thyroid-stimulating hormone (TSH), the main hormonal regulator of the thyroid (Vassart and Dumont, 1992), via the TSH receptor/cAMP pathway (Laglia et al., 1996; Endo et al., 1997).

Recent evidence indicates that the thyroid NIS gene is also subject to regulation by non-TSH signaling pathways (Nicola et al., 2010; Ringseis et al., 2013). In this regard, it has been recently reported that the NIS gene is regulated by 2 transcription factors, sterol regulatory element-binding protein (SREBP)-1c and SREBP-2 (Hua et al., 1993; Yokoyama et al., 1993), in rat thyrocytes (Ringseis et al., 2013). The SREBP are highly conserved through evolution from fungi to mammals (Osborne and Espenshade, 2009) and play a key role in the regulation of lipid homeostasis. In all mammals, the SREBP-1c isoform preferentially activates genes involved in fatty acid and triacylglycerol synthe- 
sis, whereas SREBP-2 mainly activates genes involved in cholesterol metabolism (Osborne and Espenshade, 2009). Both, SREBP-1c and SREBP-2 are synthesized as inactive precursors (pSREBP) with a molecular weight of about $125 \mathrm{kDa}$ and are located as complexes with other proteins in the endoplasmic reticulum membrane. Upon a decrease of cellular cholesterol content, pSREBP are escorted to the Golgi apparatus, where they are proteolytically processed leading to the release of their active N-terminal domain, called nuclear SREBP (nSREBP), with a molecular weight of about $70 \mathrm{kDa}$ (Espenshade et al., 2002; Yang et al., 2002). The nSREBP bind to sterol regulatory elements (SRE) in the regulatory region of target genes and, thereby, initiate gene transcription (Horton et al., 2002).

Using molecular biological techniques a functional SRE could be identified in the NIS 5'-flanking region indicating that the rat NIS gene is a SREBP target gene (Ringseis et al., 2013). Interestingly, transcriptional activation of the NIS 5'-flanking region by nSREBP occurred independent of the presence of nucleotide sequences essential for thyroid-specific NIS gene regulation like the NIS upstream enhancer region and the proximal promoter (Ringseis et al., 2013), indicating that SREBP-dependent regulation of the NIS gene may be of greater importance in extra-thyroidal tissues, in which NIS is also functional but TSH is not the primary regulator. One of these tissues is the mammary gland.

In contrast to the constitutive expression of NIS in the thyroid, investigations in rats and mice showed that mammary gland NIS is functionally expressed in the mammary epithelium from the end of pregnancy and throughout lactation until weaning (Tazebay et al., 2000). In the lactating mammary gland, NIS is responsible for the secretion of iodide into the milk and thus essential for providing iodide for thyroid hormone biosynthesis in the neonate in general and in the newborn calf during the colostral phase in specific. According to studies in laboratory rodents, the inducible expression of NIS in mammary epithelial cells during lactation involves the cooperative action of the lactogenic hormones oxytocin, prolactin, and estrogens (Tazebay et al., 2000), yet the mechanism of NIS gene regulation by these hormones is not completely clear. Studies about NIS gene regulation and iodide uptake in bovine mammary epithelial cells or bovine mammary gland are completely lacking. However, it has long been known that feedstuff containing glucosinolates, like coproducts from oil production (rapeseed meal, rapeseed press cake) and feed from other cruciferous plants (kale), lowers iodine excretion via the milk of cows (Piironen and Virtanen, 1963). Earlier studies with dairy cows showed that feeding a ration with rapeseed products from old conventional rapeseed varieties with glucosinolate con- centrations of 50 to $100 \mathrm{mmol} / \mathrm{kg}$ reduced iodine content of cow milk by 50 to $75 \%$ (Iwarsson, 1973; Papas et al., 1979) compared with a ration containing no rapeseed but having the same iodine concentration. This effect is mediated by the degradation products of glucosinolates in the animal's body like thiocyanates and isothiocyanates, which are known to competitively inhibit iodide uptake by NIS in the thyroid and the mammary gland (Yoshida et al., 1998; Rillema et al., 2000). Thus, these findings indicate that mammary gland NIS of cattle plays also a role for the provision of iodide to the calf, in modern dairy production at least during the colostral phase. Due to the unique function of mammary gland NIS for iodide transfer into the milk, it is very likely that NIS in the mammary gland of cattle is regulated at least similarly as in other mammals.

Noteworthy, SREBP are strongly induced, activated, or both after parturition and throughout lactation in the mammary gland as shown in cattle (Bionaz and Loor, 2008), sheep (Barber et al., 2003), and mice (Rudolph et al., 2010). The physiological significance of SREBP activation in the lactating mammary gland is to stimulate the synthesis of fatty acids, triacylglycerols, phospholipids, and cholesterol (Rudolph et al., 2007; Rudolph et al., 2010; Mani et al., 2010) and thus to maintain lipid content in the milk and to provide lipophilic nutrients to the suckling neonate. In line with the key function of SREBP-1c for fatty acid and triacylglycerol synthesis, CLA isomers, which cause a reduction of milk fat content in dairy cows (Loor and Herbein, 1998; Perfield et al., 2007) and many other species, such as rats (Ringseis et al., 2004), sheep (Lock et al., 2006), and goats (Lock et al., 2008), were found to inhibit SREBP-1c maturation (Peterson et al., 2004) and decrease expression of SREBP-1c (Harvatine and Bauman, 2006) in mammary epithelial cells. Whether SREBP may also play a role in the secretion of nonlipid nutrients like iodide through regulation of mammary gland NIS and thus are generally important for maintaining the nutrient content of the milk is currently unknown. In view of recent evidence that the NIS gene is transcriptionally regulated by SREBP in the thyroid, the present study aimed to test the hypothesis that SREBP are regulators of the NIS gene and iodide uptake in mammary epithelial cells. As a mammary epithelial cell model the human breast adenocarcinoma cell line MCF-7 was used because it is a well-established mammary epithelial cell model to investigate the regulation of mammary gland NIS and NIS-specific iodide uptake (Kogai et al., 2000). In contrast, bovine mammary epithelial cell lines, such as BMEG + HM (Schmid et al., 1983), HH2a (Huynh and Pollak, 1995), ET-C (Zavizion et al., 1996), and Mac-T (Huynh et al., 1991), have not been characterized yet for iodide uptake 
or NIS expression. In addition, in spite of their bovine origin these cell lines are not necessarily better models of the bovine mammary gland because they either do not express lactation-specific proteins $(\mathrm{BMEC}+\mathrm{H}$, HH2A, ET-C) or in the case of Mac-T cells show a poor lactation phenotype compared with bovine mammary tissue (Hosseini et al. 2013).

\section{MATERIALS AND METHODS}

\section{Cell Culture}

Cells of MCF-7, a breast adenocarcinoma cell line (Soule et al., 1973) and with inducible expression of NIS by all-trans retinoic acid (ATRA; Kogai et al., 2000), were obtained from Cell Lines Service (Eppelheim, Germany) and grown at $37^{\circ} \mathrm{C}$ in a humidified atmosphere composed of $95 \%$ air and $5 \% \mathrm{CO}_{2}$ in Dulbecco's modified Eagle medium (DMEM; Gibco/Life Technologies, Darmstadt, Germany) and 10\% fetal bovine serum (Gibco/Life Technologies). Growth medium was changed every $2 \mathrm{~d}$. After reaching a confluence of $80 \%$, the cells were either sub-cultivated or used for experiments. Experimental conditions [concentrations of chemicals, such as ATRA and 25-hydroxycholesterol (25-HC), and duration of experiment] are indicated in the Results section and figure legends.

\section{Cell Viability Assay}

The 3-(4,5-dimethylthiazol-2-yl)-2,5-diphenyltetrazolium bromide (MTT) assay was used to assess cell viability in response to ATRA, 25-HC, small interfering RNA (siRNA) molecules, and expression plasmids. The MCF-7 cells were seeded in 96-well and 24-well cul- ture plates at a density of $1 \times 10^{4}$ and $5 \times 10^{4}$ cells per well, respectively, and after reaching $80 \%$ confluence incubated with different concentrations of ATRA (0, $0.25,0.5,1,2,5$, and $10 \mu M)$ or $25-\mathrm{HC}(0,2.5,5,10,15$, 25 , and $50 \mu M$ ) or transfected with siRNA molecules as described in the RNA interference section or with reporter gene plasmids, SREBP expression plasmids or empty plasmid and selected luciferase reporter vectors as described in the transient transfection section. All cells were treated with the same vehicle concentration [1\% vol/vol, ethanol, or dimethyl sulfoxide (DMSO)]. The MTT assay was performed as described recently (Gessner et al., 2012), with the exception that MCF-7 cells were incubated with the MTT solution for $4 \mathrm{~h}$. Cell viabilities of treated cells are presented relative to that of control cells, which was set to $100 \%$.

\section{RNA Isolation and Quantitative Real-Time PCR}

For quantitative real-time PCR (qPCR) analysis, MCF-7 cells were seeded in 24-well plates and incubated as indicated. Total RNA extraction, cDNA synthesis, and qPCR were performed as described recently for FRTL-5 cells (Ringseis et al., 2013). Gene-specific primer pairs and their features are listed in Table 1.

\section{Western Blotting}

For Western blotting of precursor and nuclear SREBP-1 and SREBP-2 and NIS, MCF-7 cells were seeded in 6-well plates and incubated as indicated. To prevent degradation of SREBP, MCF-7 cells were treated with $25 \mu \mathrm{g} / \mathrm{mL}$ of the calpain inhibitor $N$-acetyl-LeuLeu-Norleucinal $3 \mathrm{~h}$ before cell harvesting according to Hua et al. (1996). Cytosolic and nuclear fractions from

Table 1. Characteristics of gene-specific primers used for quantitative real-time PCR

\begin{tabular}{|c|c|c|c|}
\hline Gene symbol & Primer sequence (forward, reverse; $5^{\prime}$ to $3^{\prime}$ ) & $\begin{array}{l}\text { Product } \\
\text { size (bp) }\end{array}$ & $\begin{array}{l}\text { Gene } \\
\text { accession no. }\end{array}$ \\
\hline \multicolumn{4}{|l|}{ Reference gene } \\
\hline$A T P 5 B$ & TCGCGTGCCATTGCTGAGCT, CGTGCACGGGACACGGTCAA & 218 & NM_001686 \\
\hline$G A P D H$ & GCCTTCCGTGTCCCCACTGC, CAATGCCAGCCCCAGCGTCA & 211 & NM_002046 \\
\hline EIF4A2 & GCGCAAGGTGGACTGGCTGA, GCACATCAATCCCGCGAGCC & 170 & NM_001967 \\
\hline SDHA & CCAAGCCCATCCAGGGGCAAC, TCCAGAGTGACCTTCCCAGTGCCAA & 100 & NM_004168 \\
\hline FASN & GGCCGTGGTCTTGAGAGATG, TAGTTGCTCTGTCCCGCATTG & 189 & NM_004104 \\
\hline GPAM & AATGGTGAACAACTGGGCAAAC, ATCCACTCGGACACAACCATAG & 105 & NM_001244949 \\
\hline$H M G C R$ & GACAGGATGCAGCACAGAATG, TTGAACACCTAGCATCTGCAAAC & 179 & NM_000859 \\
\hline$L D L R$ & GTCAGCTCCACAGCCGTAAG, CCCAGAGCTTGGTGAGACATTG & 128 & NM_000527 \\
\hline$N I S$ & TGCGGGACTTTGCAGTACATT, TGCAGATAATTCCGGTGGACA & 133 & NM_000453 \\
\hline$S R E B P-1 c$ & CGGAGCCATGGATTGCACTTTC, GATGCTCAGTGGCACTGACTCTTC & 328 & NM_001005291 \\
\hline$S R E B P-2$ & TAGGCAGTCTGGTGGACAATG, GTCTGGCTCATCTTTGACCTTTG & 179 & NM_004599 \\
\hline
\end{tabular}


cells were prepared using the Nuclear Extract Kit from Active Motif (La Hulpe, Belgium). Protein concentrations of cell fractions were determined by the bicinchoninic acid protein assay kit (Interchim, Montluçon, France) with BSA as the standard. From the fractions, $10 \mu \mathrm{g}$ (from the cytosolic fraction for NIS) and $20 \mu \mathrm{g}$ of protein (from both the cytosolic and nuclear fraction for precursor and nuclear SREBP-1 and SREBP-2) were separated by SDS-PAGE (7.5-12.5\%) and electrotransferred onto nitrocellulose membranes (Pall Corporation, Pensacola, FL). Loading of equal amounts of protein in each lane was verified by Ponceau S (Carl Roth, Karlsruhe, Germany) staining. After incubating the membranes overnight at $4^{\circ} \mathrm{C}$ in blocking solution, membranes were incubated with primary antibodies anti-rabbit SREBP-1 and anti-rabbit SREBP-2 (both 1:2,000; St. Cruz, Heidelberg, Germany), anti-rabbit NIS [1:2,000; kindly provided by Nancy Carrasco, Department of Cellular and Molecular Physiology, Yale University School of Medicine, New Haven, CT (Levy et al., 1997)] and anti-mouse $\beta$-actin (1:10,000; Abcam, Cambridge, UK) as a reference protein to control for adequate normalization at room temperature (RT) for $2 \mathrm{~h}$. The membranes were washed and then incubated with horseradish peroxidase-conjugated secondary antibodies anti-rabbit IgG (1:10,000; Sigma-Aldrich, Taufkirchen, Germany) for SREBP-1, SREBP-2 and NIS, and anti-mouse IgG (1:10,000; Abcam) for $\beta$-actin at RT for $2 \mathrm{~h}$. Afterward, blots were developed using enhanced chemiluminescence (ECL) Plus (GE Healthcare, München, Germany). The signal intensities of specific bands were detected with a Bio-Imaging system (Syngene, Cambridge, UK) and quantified using Syngene GeneTools software (nonlinear dynamics; Syngene).

\section{lodide Uptake}

For iodide uptake, MCF-7 cells were seeded in 24well plates and incubated as indicated. Iodide uptake was carried out as described recently (Ringseis et al., 2013) with minor modifications. In brief, the medium was removed and cells were washed with warm $\left(37^{\circ} \mathrm{C}\right)$ Hanks' buffered salt solution (HBSS). Subsequently, $0.5 \mathrm{~mL}$ of HBSS containing $\mathrm{Na}^{125} \mathrm{I}(0.3 \mu \mathrm{Ci} / \mathrm{mL})$ was immediately added to each well and cells incubated at $37^{\circ} \mathrm{C}$ for $1 \mathrm{~h}$. To distinguish between total iodide uptake and NIS-specific uptake, the incubation was performed both in the absence (total iodide uptake) and presence (NIS-specific uptake) of $1 \mathrm{mM} \mathrm{KClO}_{4}$, a specific inhibitor of iodide uptake via NIS. The incubation was terminated by aspiration of the medium. After rinsing 2 times with ice-cold HBSS, cells were lysed with $0.5 \mathrm{~mL}$ of $0.5 \mathrm{M} \mathrm{NaOH}$ with shaking at RT for $30 \mathrm{~min}$. The cell lysate from each well was transferred in a counter vial for scintillation counting (Perkin Elmer Liquid Scintillation Analyzer Tri-Carb 2900TR, Rodgau, Germany).

\section{RNA Interference}

Knockdown variants of MCF-7 cells expressing low levels of SREBP-1c and SREBP-2, respectively, were produced by siRNA-mediated gene knockdown. For this purpose, MCF-7 cells were seeded in 24-well and 6-well plates for qPCR and Western blotting, respectively, and after reaching a confluence of 70 to $80 \%$, cells were transfected using Lipofectamine 2000 Reagent (Invitrogen) and gene-specific Stealth RNAi molecules (SREBP-1c/-2 siRNA; Invitrogen) targeting human $S R E B P-1 c$ and $S R E B P-2$, respectively, at a final concentration of $50 \mathrm{n} M$ for $24 \mathrm{~h}$ according to the manufacturer's protocol. To control for unspecific knockdown effects, control cells were transfected with a control RNAi molecule (control siRNA) that was not homologous to any human gene sequence. After $24 \mathrm{~h}$, transfection medium was aspirated and cells were incubated with growth medium for $24 \mathrm{~h}$. The knockdown effect was assessed by qPCR and Western blotting. The siRNA sequences were as follows (sense, antisense): SREBP-1c siRNA (5'-UCAGAUACCACCAGCGUCUACCAUA-3', 5'-UAUGGUAGACGCUGGUGGUAUCUGA-3'), SREBP-2 siRNA (5'-GAGGCAGGCUUUGAAGACGAAGCUA-3'， 5'-UAGCUUCGUCUUCAAAGCCUGCCUC- $3^{\prime}$ ), and control siRNA (5'-UUCUCCGAACGUGUCACGUdTdT-3', 5' GUGACACGUUCGGAGAAdTdT-3').

\section{Bioinformatics}

For the identification of putative SREBP-binding sites, in silico analysis was performed using TFBIND software developed for searching transcription factor binding sites including TATA boxes, GC boxes, CCAAT boxes, and transcription start sites (Tsunoda and Takagi, 1999). The TFBIND tool uses weight matrix of transcription factor database TRANSFAC (Wingender et al., 2001).

\section{Plasmid Construction and Site-Directed Mutagenesis}

Using cDNA and genomic DNA sequences from National Center for Biotechnology Information GenBank (accession numbers NM_000453 and NC005796), a 630-bp $h N I S$ promoter fragment (from -280 to +350 relative to transcription start site) was PCR amplified from a genomic DNA resource (BAC RP11-343E23; 
Table 2. Sequences of 5'-primers used for PCR amplification of human sodium/iodide symporter (hNIS) reporter constructs ${ }^{1}$

\begin{tabular}{llc}
\hline $\begin{array}{l}\text { hNIS } \\
\text { construct }\end{array}$ & Oligonucleotide sequence $\left(5^{\prime}\right.$ to $\left.3^{\prime}\right)$ & $\begin{array}{c}\text { PCR product } \\
\text { size (bp) }\end{array}$ \\
\hline$-244 /+350$ & AAACTCGAGATCACAGTGCATGGGGATG & 594 \\
$-160 /+350$ & AAACTCGAGCAGATAGCCTGTCCTGGCCT & 510 \\
$+164 /+350$ & AAACTCGAGCATAGATTCCTAACCCAGGG & 186 \\
$+263 /+350$ & AAACTCGAGTCCTGCCTCCTCGGCCCCT & 87 \\
\hline
\end{tabular}

${ }^{1}$ The sequence of the common 3 '-primer is presented in the corresponding methods description in Plasmid Construction and Site-Directed Mutagenesis.

BACPAC Resources, Oakland, CA) using the following primer pair: 5'-AGGAAGCTTCATGAGGGCGGGTGCGGAG-3' (forward) and 5'-AAACTCGAGCCTGTCAACAGCAGACAGTG-3' (reverse). The generated PCR fragment with $X h o I$ and HindIII restriction sites introduced at the $5^{\prime}$ and $3^{\prime}$ ends was subcloned into the XhoI and HindIII digested pGL4.10 [luc2] vector (Promega, Mannheim, Germany) upstream of the luciferase reporter gene. The $h N I S$ promoter truncation constructs $(-244 /+350,-160 /+350$ and $+164 /+350$ and $+263 /+350)$ were PCR amplified from the parental pGL4.10-hNIS-280/+350 promoter construct using the abovementioned 3 -primer and different 5 '-primers (Table 2). All generated PCR fragments were subcloned into XhoI and HindIII sites of pGL4.10 [luc2] vector (Promega) upstream of the luciferase reporter gene. Mutated hNIS reporter gene constructs were generated by selectively introducing a mutation in the putative SRE using the QuikChange XL Site-Directed Mutagenesis Kit from Stratagene Europe (Amsterdam, the Netherlands) according to the manufacturer's protocol using the following oligonucleotides: SRE-179mut (forward: 5'-GCCCTCCCCGATACCgttCCCTGCAGCCACCCAG-3', reverse: 5'-CTGGGTGGCTGCAGGGaacGGTATCGGGGAGGGC-3'), E-box-like SRE-38mut (forward: 5'-CTGCAACCCACAATtgtaAGCTGCTCCCGTAAG-3', reverse: 5'-CTTACGGGAGCAGCTtacaATTGTGGGTTGCAG-3'). The artificial reporter gene constructs containing 2 copies of either wild-type or mutated E-box-like SRE-38 were prepared by annealing the oligonucleotides (wild-type Ebox-like SRE-38: XhoI-TCGACTGCAACCCACAATCACGAGCTGCTCCCCCACAATCACGAGCTGCTCCCGTAAG, HindIII-AGCTCTTACGGGAGCAGCTCGTGATTGTGGGGGAGCAGCTCGTGATTGTGGGTTGCAG; mutated E-box-like SRE-38: XhoI-TCGACTGCAACCCACAATtgtaAGCTGCTCCCCCACAATtgtaAGCTGCTCCCGTAAG, HindIII-AGCTCTTACGGGAGCAGCTtacaATTGTGGGGGAGCAGCTtacaATTGTGGGTTGCAG) and subcloning into XhoI and HindIII sites of pGL4.23 $[\mathrm{luc} 2 / \mathrm{minP}]$ vector (Promega), which contains the min- imal promoter minP followed by the luciferase reporter gene luc2. To confirm the integrity of all plasmids and to control for the intended mutations and the absence of any unexpected mutations, the cloned DNA fragments were sequenced. The generation of the positive control reporter gene construct containing 2 copies of the human $L D L R$ ( $h L D L R)$-SRE and expression plasmids for nSREBP-1c (AA 1-448) and nSREBP-2 (AA 1-460) has been described recently (Ringseis et al., 2013).

\section{Transient Transfection and Dual Luciferase Assay}

For transient transfection, MCF-7 cells were seeded in 96-well plates and transiently transfected with $50 \mathrm{ng}$ of the generated reporter gene constructs and co-transfected with $50 \mathrm{ng}$ of either nSREBP-1c or nSREBP-2 expression plasmids or $50 \mathrm{ng}$ of the empty expression plasmid (pcDNA3.1) using FuGENE 6 transfection reagent (Roche Diagnostics, Mannheim, Germany) according to the manufacturer's protocol. For normalization of transfection efficiency, cells were co-transfected with $5 \mathrm{ng}$ of pGL4.74 [luc2] vector (Promega), which encodes for the Renilla luciferase, as an internal control. In addition, cells were transfected with $50 \mathrm{ng}$ of either pGL4.10 [luc2] vector or pGL4.23 [luc2/minP] vector (both from Promega) or the $2 \times$ hLDLR-SRE luciferase reporter vector, containing 2 copies of the SRE-1 from hLDLR, as negative and positive controls. After $12 \mathrm{~h}$, transfection medium was aspirated and cells were incubated for $12 \mathrm{~h}$ with growth medium. Subsequently, medium was aspirated from the cell layer and cells were washed with $1 \times$ PBS and lysed with passive lysis buffer (Promega). Luciferase activities of cell lysates were measured using Beetle-Juice and Renilla-Juice Kits from PJK (Kleinblittersdorf, Germany). Normalized luciferase activities were calculated by dividing the luciferase activity of each construct by that of the corresponding empty vectors, pGL4.10 or pGL4.23 (Inoue et al., 2011). Results are shown relative to cells transfected with the empty expression plasmid pcDNA3.1, which were set to 1 . 


\section{Electrophoretic Mobility Shift Assay}

Electrophoretic mobility shift assays were performed as described recently in detail (Wen et al., 2010). In brief, recombinant rat nSREBP-1c and nSREBP-2 were in vitro translated from the corresponding expression plasmids using the TNT T7 Quick Coupled Transcription/Translation System (Promega) according to the manufacturer's protocol. Annealed oligonucleotides spanning either the wild-type or the mutated hNIS E-box-like SRE-38 of $h N I S$ 5'-flanking region were end-labeled with digoxigenin (DIG) using the DIG Gel Shift Kit, 2nd Generation (Roche). In addition, annealed and DIG-labeled oligonucleotides spanning either the wild-type or the mutated hLDLR-SRE were used as specific and nonspecific control. Sequences of oligonucleotides were as follows: wild-type hNIS E-boxlike SRE-38 (forward: TCGATGCAACCCACAATCACGAGCTGCTCCCGTAA, reverse: AGTCTTACGGGAGCAGCTCGTGATTGTGGGTTGCA), mutated hNIS E-box-like SRE-38 (forward: TCGATGCAACCCACAATtgtaAGCTGCTCCCGTAA, reverse: AGTCTTACGGGAGCAGCTtacaATTGTGGGTTGCA), wild-type hLDLR-SRE (forward: GTAGATTTTTGAAAATCACCCCACTGCAAACTCC, reverse: $\quad$ GGGAGGAGTtTGCAGTGGGGTGATTTTCAAAAAT), mutated hLDLR-SRE (forward: GTAGATTTTTGAAAgTCAaaCCgtTGCAAACTCC, reverse: GGGAGGAGTtTGCAacGGttTGAcTTTCAAAAAT). For competition experiments, recombinant proteins were incubated with DIGlabeled hNIS E-box-like SRE-38 probe and increasing excess of unlabeled specific probe (hLDLR-SRE).

\section{Statistical Analysis}

All data represent means and SD. In all figures showing numerical data, with the exception of data from ${ }^{125}$ Iodide uptake, the means and SD were calculated from the means for the same treatments of 3 independent experiments. The means and SD for ${ }^{125}$ Iodide uptake were calculated from 3 replicates within one independent experiment, but the data from the one experiment shown are representative for the 2 other independent experiments. Statistical analysis was performed using the Minitab statistical software (Rel. 13.0, State College, PA). Data (residuals) of each independent experiment were analyzed for normality of distribution (Anderson-Darling test). Because all data showed normal distribution, one-way ANOVA was applied to evaluate the effect of treatment. Effects were considered significant if $P<0.05$. If one-way ANOVA revealed significant effects, a post-hoc comparison (Fisher's multiple comparison) was applied.

\section{RESULTS AND DISCUSSION}

\section{Sterol-Mediated Inhibition of SREBP Maturation}

To test the hypothesis that the NIS gene is regulated by SREBP in MCF-7 cells, we first studied the effect of reducing the cellular levels of transcriptionally active nSREBP by the oxysterol 25-HC. Oxysterols such as 25 -HC serve as biologically active molecules for regulation of lipid metabolism in all animal cells (Gill et al., 2008), and are formed endogenously from intracellular cholesterol by mitochondrial sterol 27-hydroxylase following delivery of cholesterol into the mitochondria ( $\mathrm{Li}$ et al., 2006, 2007). Thus, when intracellular cholesterol levels are increased, cholesterol is transported into the mitochondria and 25-HC is synthesized. However, 25$\mathrm{HC}$ does not accumulate in the cell because 25-HC is subsequently sulfated by sulfotransferase $2 \mathrm{~B} 1 \mathrm{~b}$ to form 25-HC 3-sulfate (Ren et al., 2006), which inhibits proteolytic processing of SREBP-1 and SREBP-2 and thereby inhibits lipid biosynthesis (Ma et al., 2008). Thus, $25-\mathrm{HC}$ is a useful approach to study the effect of decreased cellular levels of nSREBP-1 and nSREBP-2 (Nohturfft et al., 2000; DeBose-Boyd et al., 2001; Sato, 2010). Incubation experiments with $25-\mathrm{HC}$ in MCF-7 cells were performed at a concentration of $5 \mu M$, which is within the concentration range shown to be successful in reducing levels of nSREBP-1 and nSREBP-2 in other cell types, such as hepatocytes (DeBose-Boyd et al., 2001) and thyrocytes (Ringseis et al., 2013). The MTT assay revealed that this concentration of $25-\mathrm{HC}$ did not impair the viability of MCF-7 cells (data not shown).

Incubation experiments with $25-\mathrm{HC}$ in $\mathrm{MCF}-7$ cells were performed in the presence of ATRA $(1 \mu M)$, which is a known inducer of NIS gene transcription and iodide uptake in this cell line (Kogai et al., 2000; Alotaibi et al., 2010). This was necessary because NIS mRNA is only barely detectable and iodide uptake is very low in the absence of ATRA (Kogai et al., 2000). The ATRA was also found not to be toxic for MCF-7 cells up to a concentration of $10 \mu \mathrm{M}$ as shown by an MTT assay (data not shown). As illustrated in Figures 1A and 1B, treatment of MCF-7 cells with ATRA alone had no effect on the mRNA concentrations of SREBP$1 c$ and SREBP-2 and the protein concentrations of nSREBP-1 and nSREBP-2 compared with treatment with DMSO (control), indicating that ATRA does not interfere with SREBP maturation. Combined treatment of MCF-7 cells with ATRA and 25-HC strongly reduced the mRNA concentrations of $S R E B P-1 c$ and $S R E B P-2$ and the protein concentrations of nSREBP-1 and nSREBP-2 compared with treatment with either ATRA or DMSO (Figures 1A and 1B). 
A



B

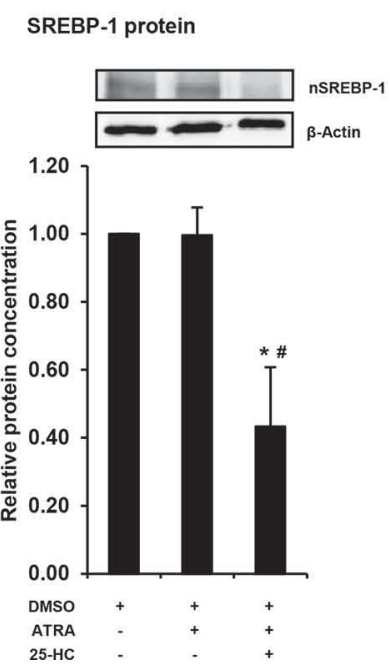

C
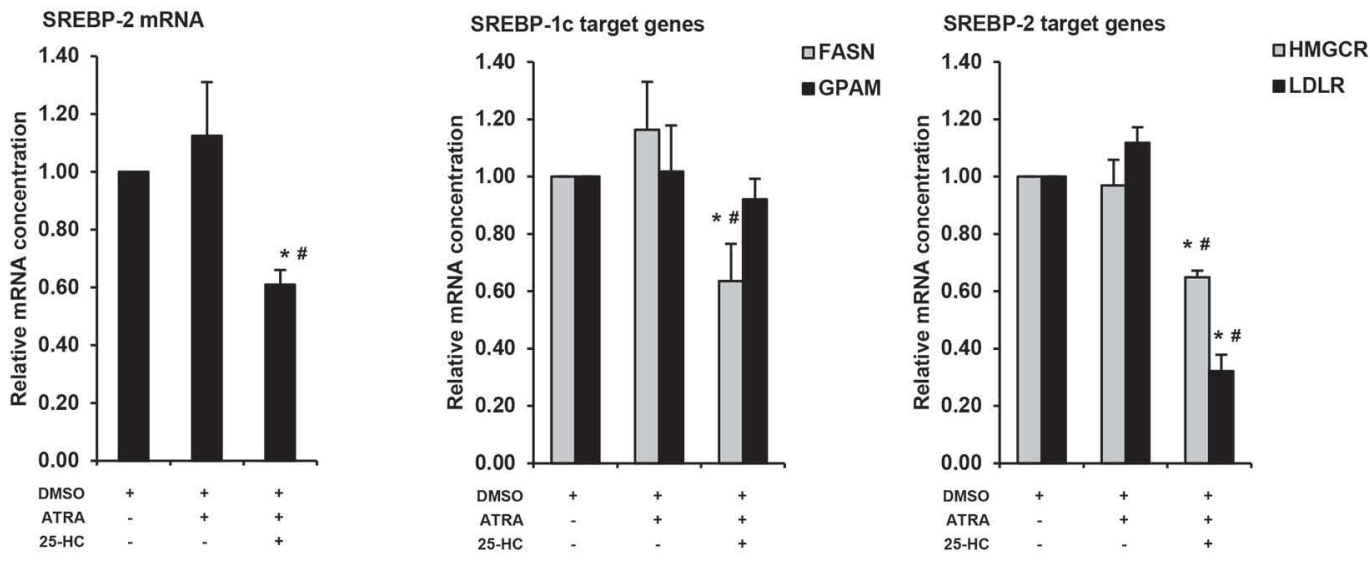

$E$


Figure 1. Sterol-mediated inhibition of sterol regulatory element-binding proteins (SREBP) maturation reduces expression of sodium/iodide symporter (NIS) and NIS-specific iodide uptake in MCF-7 cells. The MCF-7 cells were grown in Dulbecco's modified Eagle medium with $10 \%$ fetal calf serum until $70 \%$ confluent, and subsequently treated with either dimethyl sulfoxide (DMSO; $1 \%$ vol/vol), all-trans-retinoic acid (ATRA; $1 \mu M)$, or ATRA $(1 \mu M)$ and 25-hydroxycholesterol (25-HC; $5 \mu M$ ) for $48 \mathrm{~h}$, and analyzed for relative mRNA concentrations of $S R E B P$ $1 c$ and SREBP-2 (A), relative protein concentrations of nuclear SREBP (nSREBP)-1 and nSREBP-2 (B), relative mRNA concentrations of target genes of SREBP-1c (FASN, GPAM) and SREBP-2 (HMGCR, LDLR) (C), and NIS (D) and iodide uptake (E). (A, C, D) Bars represent relative mRNA concentrations expressed as fold of DMSO and are means \pm SD from 3 independent experiments. (B) For Western blot analysis of nSREBP-1 and nSREBP-2, MCF-7 cells were treated with the calpain inhibitor $N$-acetyl-Leu-Leu-Norleucinal (ALLN; $25 \mathrm{mg} / \mathrm{mL}) 3 \mathrm{~h}$ before cell lysis to prevent degradation of SREBP. Relative protein levels of nSREBP-1 and nSREBP-2 were determined in nuclear extracts. Bars represent relative protein concentrations expressed as fold of DMSO and are means \pm SD from 3 independent experiments. One representative immunoblot for nSREBP-1, nSREBP-2, and $\beta$-actin is shown. (E) For iodide uptake measurement, MCF-7 cells were incubated with Na ${ }^{125} \mathrm{I}(0.15$ $\mu \mathrm{Ci} /$ well $)$ for $60 \mathrm{~min}$ in the presence and absence of the NIS-specific inhibitor $\mathrm{KClO}_{4}(1 \mathrm{mM})$. Bars represent counts per minute per well and are means $\pm \mathrm{SD}$ from 3 replicates from 1 of 3 independent experiments. ${ }^{*}$ Different from DMSO $(P<0.05)$, \#Different from ATRA $(P<0.05)$.

In addition, the 25-HC-induced reduction of mRNA concentrations of $S R E B P$ and protein concentrations of nSREBP was accompanied by a decrease of the mRNA concentrations of the known SREBP-2 target genes 3-hydroxy-3-methylglutaryl coenzyme A reductase $(\boldsymbol{H M G C R})$ and $L D L R$ and of the SREBP-1c target gene fatty acid synthase $(\boldsymbol{F A S N})$ compared with treat- ment with either ATRA or DMSO (Figure 1C). These findings indicated that 25-HC inhibits SREBP maturation in MCF-7 cells as in hepatocytes (DeBose-Boyd et al., 2001) and thyrocytes (Ringseis et al., 2013).

Regarding NIS expression, Figure 1D demonstrates that ATRA alone strongly increased NIS mRNA concentration and combined treatment with ATRA and 
25-HC reduced the ATRA-induced increase of NIS mRNA concentration by approximately $20 \%$ in MCF- 7 cells. To confirm this finding on the functional level we also studied the effect of ATRA alone and of ATRA and $25-\mathrm{HC}$ on $\mathrm{Na}^{125}$ Iodide uptake into MCF-7 cells. Uptake experiments were performed in the presence and absence of $\mathrm{KClO}_{4}(1 \mathrm{mM})$, a specific inhibitor of iodide uptake via NIS. As shown in Figure 1E, total iodide uptake (absence of $\mathrm{KClO}_{4}$ ) into $\mathrm{MCF}-7$ cells was dramatically increased by treatment with ATRA alone. Treatment of MCF-7 cells with 25-HC attenuated the ATRA-induced increase of total iodide uptake by approximately $20 \%$. In the presence of $\mathrm{KClO}_{4}$ in the culture medium, neither ATRA alone nor ATRA and 25-HC stimulated iodide uptake, indicating that ATRA stimulates and 25-HC inhibits NIS-specific iodide uptake. Collectively, the results from this experimental approach provided first evidence that NIS expression and iodide uptake are regulated by SREBP in a human mammary epithelial cell line.

\section{RNA Interference-Mediated Knockdown of SREBP-1C and SREBP-2}

In a second approach of investigating the regulation of NIS expression by SREBP in MCF-7 cells, we studied the expression of NIS in MCF-7 cells with a targeted knockdown of either SREBP-1c or SREBP-2. Knockdown was induced by transfection of cells with siRNA molecules targeting either SREBP-1c or SREBP-2. Preliminary MTT assays revealed that siRNA molecules specific for SREBP-1c and SREBP-2 reduced the viability of MCF-7 cells only slightly by approximately $10 \%$ compared with cells treated with a nonspecific control siRNA for $24 \mathrm{~h}$ (data not shown). Transfection of MCF-7 cells with siRNA targeting SREBP-1c caused a reduction in the mRNA level of $S R E B P-1 c$ by about $40 \%$ (Figure $2 \mathrm{~A}$ ) and in the protein levels of pSREBP-1 and nSREBP-1 by about 25 to $40 \%$ (Figure $2 \mathrm{~B}$ ) after $48 \mathrm{~h}$ compared with transfection of cells with control siRNA. Likewise, transfection of MCF-7 cells with siRNA targeting SREBP-2 resulted in a decrease in the mRNA level of SREBP-2 by about $60 \%$ (Figure 2A) and in the protein levels of pSREBP-2 and nSREBP-2 by about 80 and $40 \%$, respectively (Figure 2B). The mRNA levels of known SREBP-1c target genes [FASN, glycerolphosphateacyltransferase $(\boldsymbol{G P A M})$ ] and SREBP-2 target genes (HMGCR, LDLR) were reduced by about 30 to $40 \%$ in MCF-7 cells transfected with siRNA targeting SREBP1c and SREBP-2, respectively (Figure 2C). Similar as observed in response to 25-HC-mediated inhibition of SREBP maturation, siRNA-mediated knockdown of
SREBP-1c and SREBP-2 reduced the mRNA level of NIS by about 45 and $25 \%$, respectively (Figure 2D). The protein level of NIS in MCF-7 cells was reduced by 25 and $40 \%$ in response to siRNA targeting SREBP-1c and SREBP-2, respectively (Figure 2E). In summary, these results provided further evidence to substantiate the hypothesis that SREBP are regulators of the NIS gene in human mammary epithelial cells.

\section{Overexpression of nSREBP-1c and nSREBP-2 Increases Expression of NIS in MCF-7 Cells}

To provide further evidence for the regulation of NIS expression by SREBP in MCF-7 cells, we explored the effect of overexpression of either nSREBP-1c or nSREBP-2 in MCF-7 cells. Successful overexpression of nSREBP-1c and nSREBP-2 was evident from markedly elevated protein concentrations of nSREBP-1c and nSREBP-2 following transient transfection of MCF-7 cells with expression plasmids for either nSREBP-1c or nSREBP-2 compared with empty plasmid (pcDNA3.1; Figure $3 \mathrm{~A}$ ). In line with this, MCF-7 cells overexpressing nSREBP-1c had approximately 40 to $60 \%$ increased mRNA concentrations of the SREBP-1c target genes FASN and GPAM compared with control cells transfected with empty plasmid (Figure 3B). In addition, the mRNA concentrations of the SREBP-2 target genes $H M G C R$ and $L D L R$ were slightly increased by about $30 \%$ in MCF-7 cells overexpressing nSREBP-1c (Figure 3B). The MCF-7 cells overexpressing nSREBP-2 had approximately $80 \%$ elevated mRNA concentrations of the SREBP-2 target genes HMGCR and LDLR. The mRNA concentrations of SREBP-1c target genes did not differ between MCF-7 cells overexpressing nSREBP-2 and control cells. Finally, we studied the effect of nSREBP overexpression on NIS expression in MCF-7 cells. As shown in Figure 3C, the mRNA concentration of NIS was 50 to $60 \%$ higher in MCF-7 cells overexpressing either nSREBP-1c or nSREBP-2 than in control cells, indicating again that NIS expression is regulated by both nSREBP-1c and nSREBP-2. In connection with the results obtained from the first 2 experimental approaches, these results suggested that mammary gland NIS is a target gene of SREBP-1c and SREBP-2, at least in the human MCF-7 cell line. Because SREBP have been initially identified as master regulators of lipid synthesis and uptake and due to this play an important role in the lactating mammary gland, our finding that SREBP regulate also NIS gene expression and iodide uptake in mammary epithelial cells may indicate that SREBP influence additional physiological functions of the mammary gland beyond lipid biosynthesis. 
nSREBP-1c and nSREBP-2 Transcriptionally Activate the 5'-Flanking Region of hNIS in MCF-7 Cells

To investigate whether the hNIS gene is transcriptionally regulated by SREBP via specific SREBP binding sites, a 630 -bp sequence upstream of the translation start site (5'-flanking region) of $h N I S$ was screened for the existence of putative SREBP responsive sequences using TFBIND software. This search revealed 5 putative SREBP responsive regions at positions $-250,-179$,
$-38,+207$, and +242 relative to the transcription start site. Three of them were more or less homolog to the classic SRE from $h L D L R$ called SRE-1 (consensus sequence: 5'-ATCACCCCAC-3'; Briggs et al., 1993), whereas 2 of them showed characteristics of both a SRE and an E-box. Such elements are called E-box-like SRE or SRE-2 (consensus sequence: 5'-ATCACGTGA-3') and frequently found in the promoter region of lipogenic genes (Amemiya-Kudo et al., 2002; Nara et al., 2002). The sequence, position, and degree of homology
A

SREBP-1c mRNA



B

SREBP-1 protein

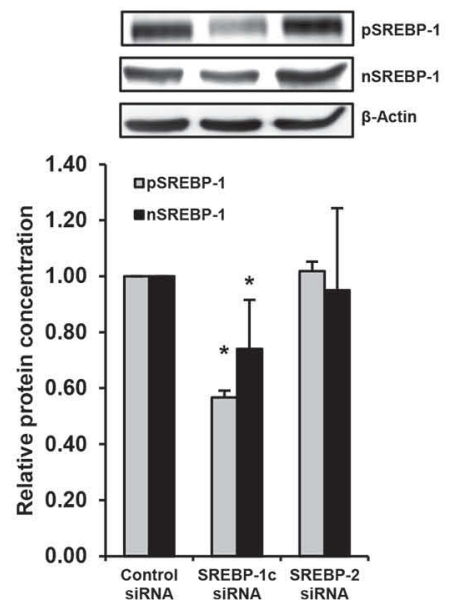

SREBP-2 mRNA

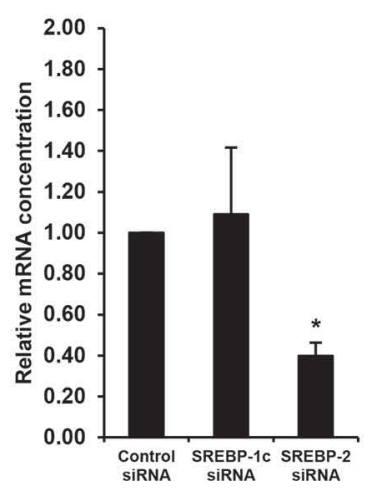

SREBP-2 protein
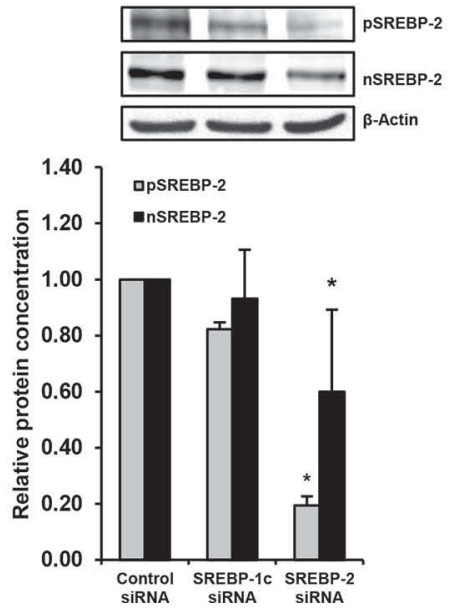

C

SREBP-1c target genes

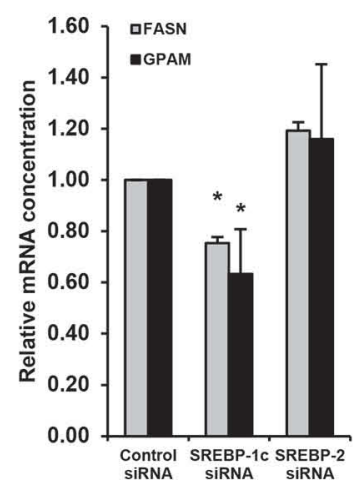

D

NIS mRNA

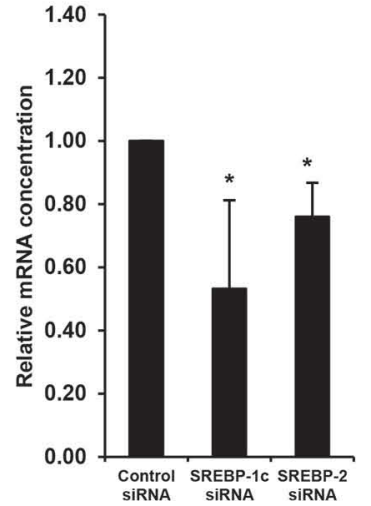

SREBP-2 target genes

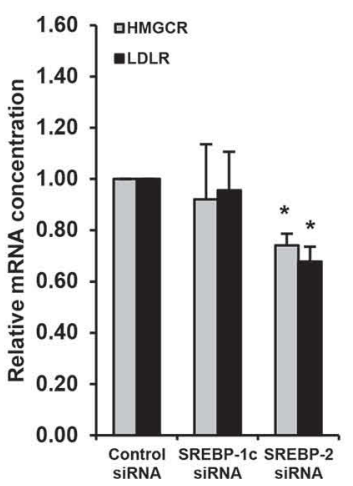

$E$

NIS protein

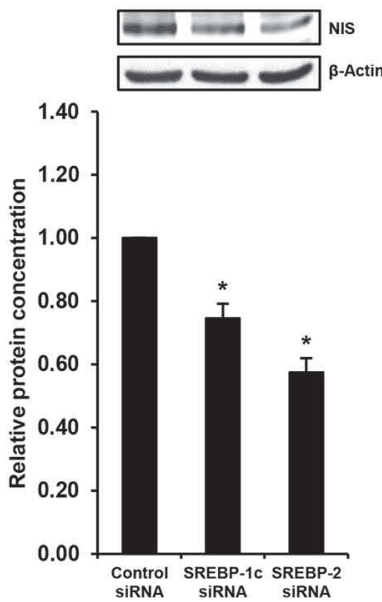

Figure 2. RNA interference-mediated knockdown of sterol regulatory element-binding proteins (SREBP)-1c and SREBP-2 reduces expression of sodium/iodide symporter (NIS) in MCF-7 cells. The MCF-7 cells were grown in Dulbecco's modified Eagle medium with $10 \%$ fetal calf serum until $70 \%$ confluent, and subsequently transfected with siRNA targeting SREBP-1c or SREBP-2 or control siRNA for 24 h. Afterward, MCF-7 cells were incubated with growth medium for an additional $24 \mathrm{~h}$ and then analyzed for relative mRNA concentrations of $S R E B P-1 c$ and SREBP-2 (A), relative protein concentrations of nuclear SREBP (nSREBP)-1 and precursor SREBP (pSREBP) and nSREBP-2 (B), relative mRNA concentrations of target genes of SREBP-1c (FASN, GPAM) and SREBP-2 (HMGCR, LDLR; C), NIS mRNA concentration (D), and NIS protein concentration (E). (A, C, D) Bars represent relative mRNA concentrations expressed as fold of control siRNA and are means \pm SD from 3 independent experiments. (B) For Western blot analysis of nSREBP-1 and nSREBP-2, MCF-7 cells were treated with the calpain inhibitor $N$-acetyl-Leu-Leu-Norleucinal (ALLN; $25 \mathrm{mg} / \mathrm{mL}$ ) $3 \mathrm{~h}$ before cell lysis to prevent degradation of SREBP. (B, E) Bars represent relative protein concentrations expressed as fold of control siRNA and are means \pm SD from 3 independent experiments. One representative immunoblot for pSREBP-1, nSREBP-1, pSREBP-2, nSREBP-2, NIS, and $\beta$-actin is shown. *Different from control siRNA $(P<0.05)$. 
A

SREBP-1 protein


SREBP-2 protein
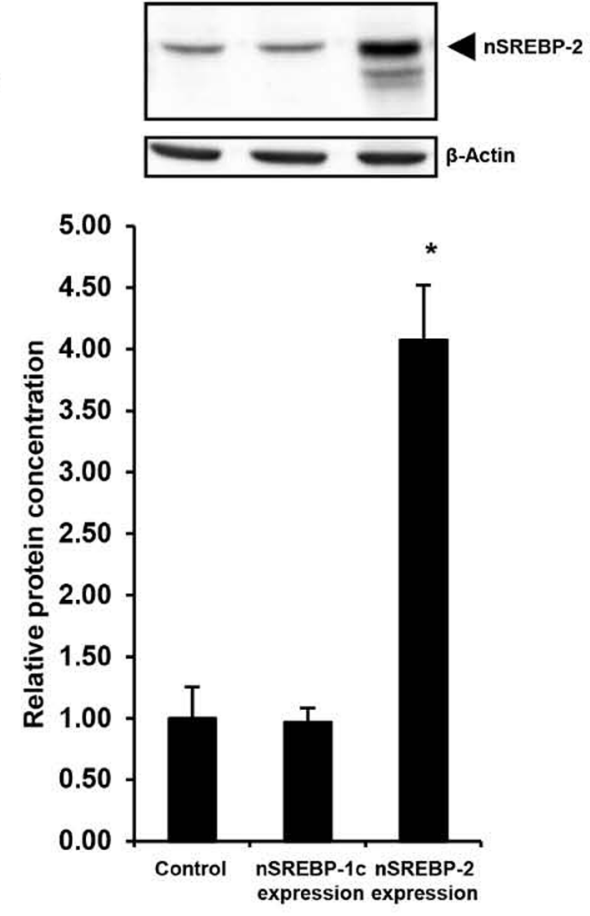

C

\section{NIS mRNA}

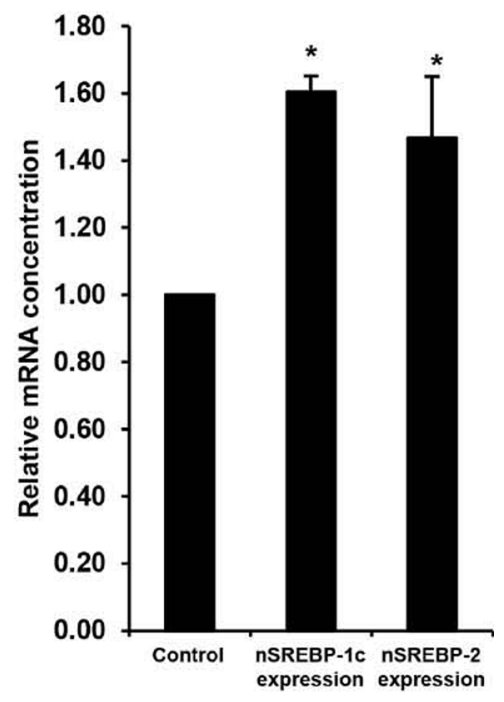

B

SREBP-1c target genes

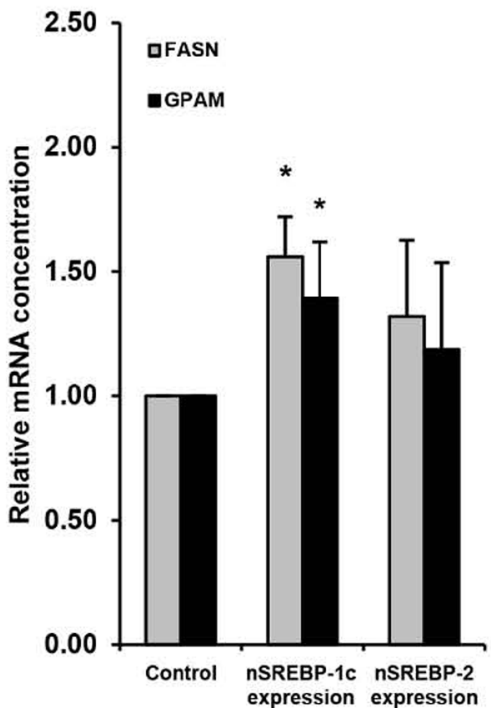

SREBP-2 target genes

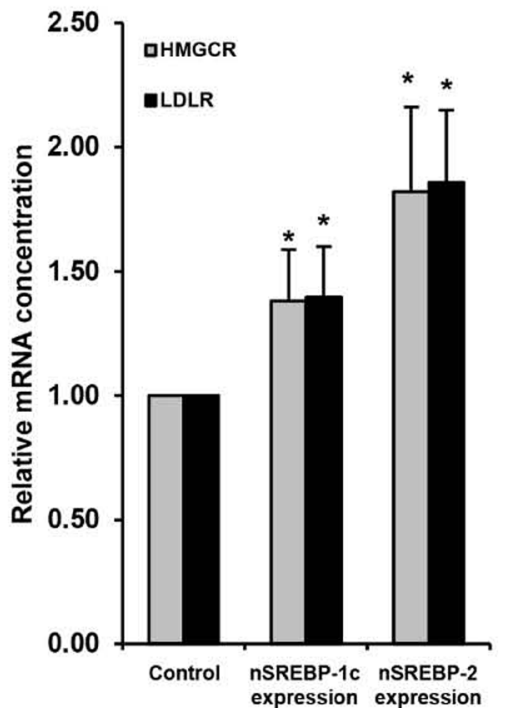

Figure 3. Overexpression of nuclear sterol regulatory element-binding protein (nSREBP)-1c and nSREBP-2 increases expression of sodium/iodide symporter (NIS) in MCF-7 cells. The MCF-7 cells were transiently transfected with expression plasmids for either nSREBP-1c or nSREBP-2 or empty plasmid (control) for $24 \mathrm{~h}$ and analyzed following a 24-h incubation period for relative protein concentrations of nSREBP-1 and nSREBP-2 (A), and relative mRNA concentrations of target genes of SREBP-1c (FASN, GPAM), SREBP-2 (HMGCR, LDLR: B), and NIS (C). (A) Relative protein levels of nSREBP-1 and nSREBP-2 were determined in nuclear extracts. Bars represent relative protein concentrations expressed as fold of control and are means \pm SD from 3 independent experiments. One representative immunoblot for nSREBP-1, nSREBP-2, and $\beta$-actin is shown. (B, C) Bars represent relative mRNA concentrations expressed as fold of control and are means \pm SD from 3 independent experiments. ${ }^{*}$ Different from control $(P<0.05)$. 
A

\begin{tabular}{cll}
\hline Putative SRE & Sequence & Position (Direction) \\
\hline SRE-1 (consensus) & $\underline{\text { ATCACCCCAC }}$ & \\
hNIS SRE-179 & ACCACCCCCT & -179 to $-170(+)$ \\
hNIS SRE+207 & CCCACCCCAG & +207 to $+216(+)$ \\
hNIS SRE+242 & $\underline{\text { ATCCTCCCAC }}$ & +242 to $+251(+)$ \\
E-box-like SRE (consensus) & $\underline{\text { ATCACGTGA }}$ & \\
hNIS E-box-like SRE-250 & $\underline{\text { TCAGGGGAT }}$ & -250 to $-242(-)$ \\
hNIS E-box-like SRE-38 & $\underline{\text { ATCACGAGC }}$ & -38 to $-30(+)$
\end{tabular}

B

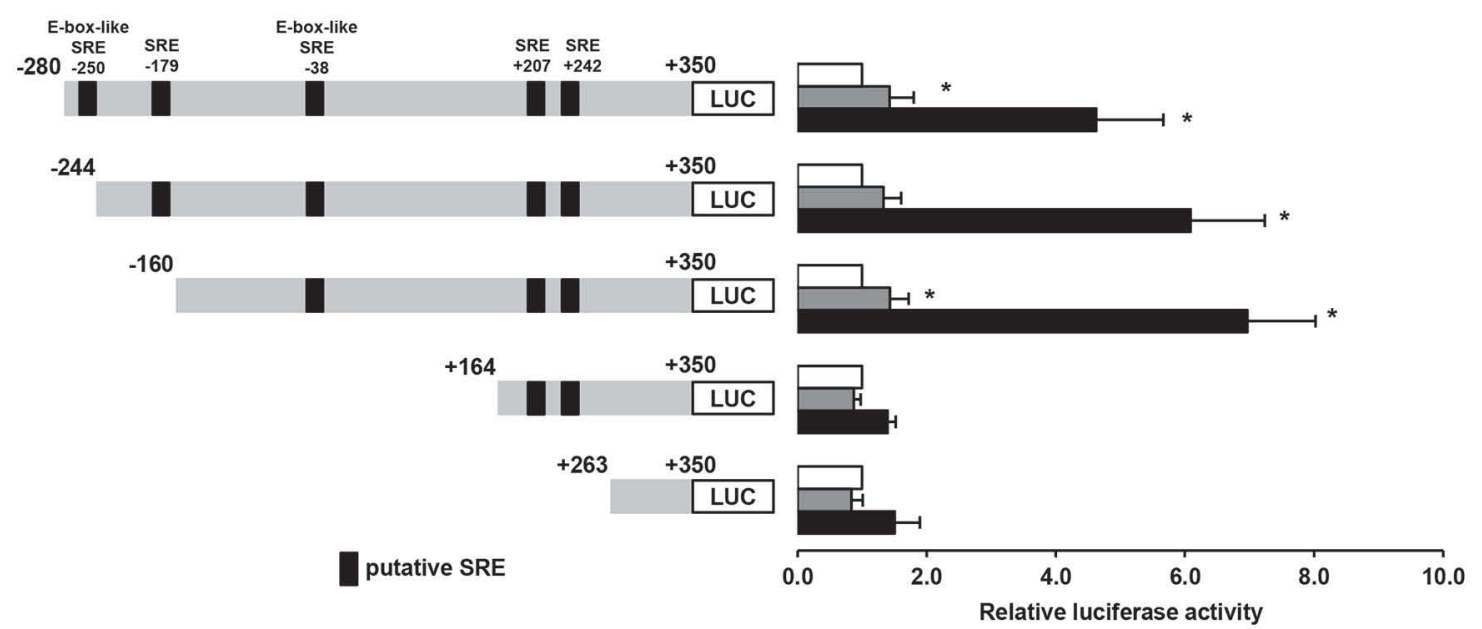

$\square$ Control $\square$ nSREBP-1C - nSREBP-2

\section{C}

2x hLDLR-SRE

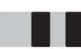

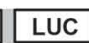

hLDLR SRE

$\square$ Control $\square$ nSREBP-1C n nSREBP-2

Figure 4. The E-box-like sterol regulatory element (SRE)-38 is critical for activation of the $5^{\prime}$-flanking region of human sodium/iodide symporter $(h N I S)$ by nuclear sterol regulatory element-binding protein (nSREBP)-1c and nSREBP-2. (A) Sequence, position, and degree of homology relative to the consensus SRE of putative SRE as indicated by MatInspector software (Genomatix, Munich, Germany) in a 630-bp sequence of the $h N I S 5^{\prime}$-flanking region (from -280 to +350 ). (B, C) MCF-7 cells were transiently transfected with either $h N I S 5^{\prime}$-flanking region luciferase reporter gene constructs containing different regions between $-280,-244,-160,+164$, and +263 , respectively, and +350 (ATG translation start site; B) or a positive control vector containing 2 copies of the $h L D L R$-SRE (C). (B, C) MCF-7 cells were co-transfected with a renilla luciferase plasmid for normalization and either expression plasmids for nSREBP-1c or nSREBP-2 or empty plasmid (control) for $12 \mathrm{~h}$. Following a 12-h incubation period with growth medium, cells were lysed and luciferase activities were measured. Bars represent relative luciferase activities expressed as fold of control and are means \pm SD from 3 independent experiments each performed in triplicate. ${ }^{*}$ Different from control $(P<0.05)$. LUC $=$ luciferase; $\min P=$ minimal promoter.

relative to the consensus SRE of these putative SRE are shown in Figure 4A.

To next examine whether this $630-b p$ sequence of the $h N I S$ 5'-flanking region is responsive to nSREBP-1c and nSREBP-2, we cloned this fragment (from -280 to +350 ) in front of a firefly luciferase reporter gene, transfected this construct together with expression vectors for either nSREBP-1c or nSREBP-2 or empty vector (pcDNA3.1) into MCF-7 cells, and measured the luciferase reporter activity following a 12-h incubation period with growth medium. Initial MTT experiments showed that $12 \mathrm{~h}$ transfection of cells with either expression vectors or empty vector together with selected luciferase reporter constructs (pGL4.10 and pGL4.10hNIS-280/+350) reduced viability of MCF-7 cells by no more than $9 \%$ compared with cells treated with vehicle only for $12 \mathrm{~h}$ (data not shown), indicating that effects from reporter gene assays are not strongly biased by the 
transfection procedure. As shown in Figure 4B, a 1.5and 4.5-fold increase occurred in the luciferase activity in response to $\mathrm{nSREBP}-1 \mathrm{c}$ and nSREBP-2, respectively, relative to empty vector in MCF-7 cells transfected with the $h N I S$ construct containing the region from -280 to +350 . This observation indicated that the $h N I S 5^{\prime}$-flanking region is responsive to nSREBP, even though the response of the luciferase reporter of hNIS construct to nSREBP-1c and nSREBP-2 was relatively small when compared with the positive control vector $2 \times$ hLDLR-SRE (Figure 4C).

To further clarify the role of the putative SRE for regulation of the $h N I S 5^{\prime}$-flanking region, we generated $4 h N I S$ 5'-end deletion reporter gene constructs, in which the SRE of the $h N I S 5^{\prime}$-flanking region were serially deleted from the $5^{\prime}$ end. Figure $4 \mathrm{~B}$ shows that the response of the luciferase reporter of the deletion constructs containing the region -244 to +350 and -160 to +350 to nSREBP-1c and nSREBP-2 was similar to that containing the region -280 to +350 , indicating that the E-box-like SRE-250 and the SRE-179 are not decisive for the responsiveness of the $h N I S 5^{\prime}$-flanking region to nSREBP. In contrast, the deletion construct containing the region +164 to +350 , which lacked the E-box-like SRE-38 and contained only 2 putative SRE in close proximity to the translation start site at positions +207 and +242 , showed no response at all to nSREBP-1c and nSREBP-2, indicating that the E-boxlike SRE-38 might be a functional SRE. Also, the deletion construct containing only the region +263 to +350 , which contains no putative SRE, exhibited almost no response to nSREBP-1c and nSREBP-2 (Figure 4B).

\section{E-Box-Like SRE-38 Is Critical for Activation of the 5'-Flanking Region of hNIS}

To clarify whether the E-box-like SRE-38 is of importance for SREBP-dependent regulation of the $h N I S$ 5 '-flanking region, we compared the luciferase reporter response of different $h N I S$ deletion reporter constructs containing the region from -244 to +350 , in which either SRE-179 or E-box-like SRE-38 or both of them were mutated by site-directed mutagenesis, with that of the nonmutated $h N I S$ deletion construct. As shown in Figure $5 \mathrm{~A}$, the reporter response of each of the hNIS deletion constructs containing a mutated E-box-like SRE38 exhibited a markedly lower response to nSREBP-1c and nSREBP-2 than those with a nonmutated Ebox-like SRE-38. Similarly, the shorter hNIS deletion construct (region from -160 to +350 ) containing the mutated E-box-like SRE-38 was clearly less responsive to nSREBP-1c and nSREBP-2 than the corresponding nonmutated deletion construct. Figure 5A also demonstrates that mutation of the SRE-179 did not influence the reporter response of the $h N I S$ deletion construct to nSREBP-1c and nSREBP-2, thus confirming the observations from the abovementioned deletion experiments (Figure 4C). To further strengthen our findings of a critical role of E-box-like SRE-38 for regulation of hNIS 5'-flanking region, we designed 2 reporter gene constructs containing 2 copies of either nonmutated or mutated E-box-like SRE-38 of hNIS in front of the luciferase reporter. As shown in Figure 5B, the reporter response of the construct containing 2 copies of the mutated E-box-like SRE-38 exhibited only a weak response to nSREBP-1c and nSREBP-2 compared with the construct with the nonmutated E-box-like SRE-38. Collectively, these findings strengthened the assumption that the E-box-like SRE-38 is functional.

\section{nSREBP-1 and nSREBP-2 Bind to the E-Box-Like SRE-38 of hNIS 5'-Flanking Region}

Because functional SRE are able to bind nSREBP, we next investigated whether nSREBP-1c and nSREBP-2 bind specifically to the E-box-like SRE-38 in the $h N I S$ 5 '-flanking region. For this end, electrophoretic mobility shift assays using a DIG-labeled double-stranded 34-bp oligonucleotide containing the E-box-like SRE-38 of $h N I S$ 5'-flanking region (hNIS E-box-like SRE-38) and in vitro translated nSREBP-1c or nSREBP-2 were performed. Reliability of electrophoretic mobility shift assays was tested using DIG-labeled oligonucleotides containing either the wild-type (positive control) or the mutated hLDLR-SRE (negative control). Figure 6 demonstrates that a shifted protein-DNA complex was formed between the wild-type hLDLR-SRE and either nSREBP-1c (lane 2, Figure 6A) or nSREBP-2 (lane 2, Figure $6 \mathrm{~B}$ ) being indicative of binding of nSREBP to hLDLR-SRE, but not between the mutated hLDLRSRE and either nSREBP-1c (lane 3, Figure 6A) or nSREBP-2 (lane 3, Figure 6B). As illustrated in lane 4 , a shifted protein-DNA complex was also formed between nSREBP-1c (Figure 6A) and nSREBP-2 (Figure $6 \mathrm{~B})$ and the wild-type hNIS E-box-like SRE-38, but not with the mutated hNIS E-box-like SRE-38 (lane 5 in Figure $6 \mathrm{~A}$ and $6 \mathrm{~B}$ ), in which 4 nucleotides of the putative SRE were mutated. Competition experiments revealed that complex formation between nSREBP-1c or nSREBP-2 and hNIS E-box-like SRE-38 was successively reduced with increasing molar excess of unlabeled specific probe (wild-type hLDLR-SRE; lanes 6-8 in Figure $6 \mathrm{~A}$ and $6 \mathrm{~B}$ ), indicating that nSREBP-1c and nSREBP-2 bind specifically to the E-box-like SRE-38 of $h N I S$ 5'-flanking region. Collectively, these results from genetic and molecular biological studies demonstrated clearly that the mammary gland NIS gene is a direct target gene of SREBP-1c and SREBP-2, at 
A

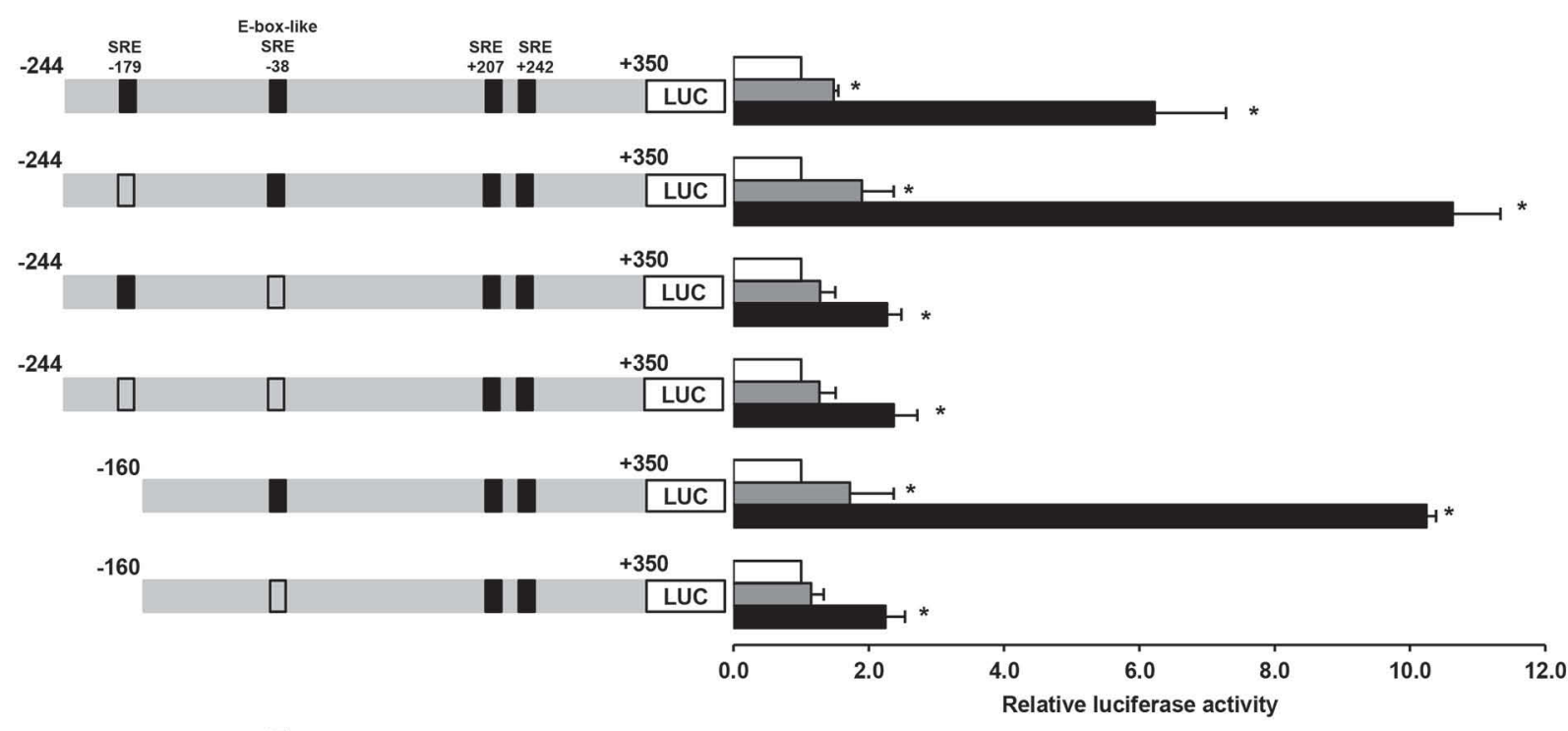

putative SRE

$\square$ mutated putative SRE

B

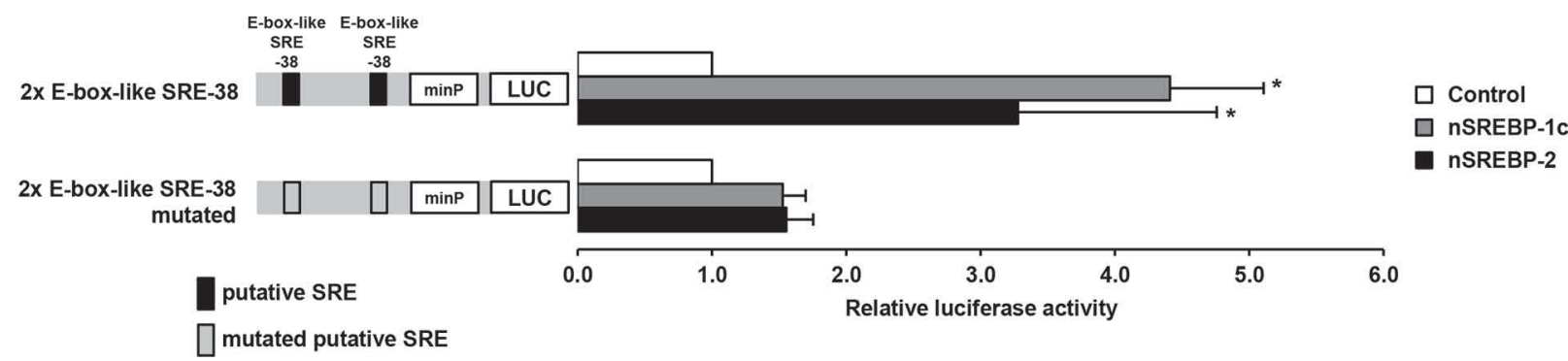

Figure 5. The E-box-like sterol regulatory element (SRE)-38 is critical for activation of the $5^{\prime}$-flanking region of human sodium/iodide symporter $(h N I S)$ by nuclear sterol regulatory element-binding protein (nSREBP)-1c and nSREBP-2. The MCF-7 cells were transiently transfected with either $h N I S$ 5'-flanking region luciferase reporter gene construct containing the region from -244 to +350 or -160 to +350 and containing either a nonmutated or a mutated SRE-179, E-box-like SRE-38, or both (A) or a reporter gene construct containing 2 copies of either nonmutated or mutated hNIS E-box-like SRE-38 (B). (A, B) MCF-7 cells were co-transfected with a renilla luciferase plasmid for normalization and either expression plasmids for nSREBP-1c or nSREBP-2 or empty plasmid (control) for $12 \mathrm{~h}$. Following a 12-h incubation period with growth medium, cells were lysed and luciferase activities were measured. Bars represent relative luciferase activities expressed as fold of control and are means \pm SD from 3 independent experiments each performed in triplicate. ${ }^{*}$ Different from control $(P<0.05)$. LUC $=$ luciferase; minP $=$ minimal promoter.

least in a human mammary epithelial cell line. Thus, it may be postulated that SREBP are more than just lipid regulators in mammary epithelial cells and even regulate the uptake of iodide into mammary epithelial cells. Provided that NIS is also regulated by SREBP in the mammary gland epithelium of cattle, the iodide content of the cow's colostrum and mature milk may be influenced by the activity of mammary gland SREBP. Thus, it appears possible that feeding CLA, which inhibit the maturation (Peterson et al., 2004) or expression (or both) of SREBP-1c (Harvatine and Bauman,
2006) in mammary epithelial cells, to cows not only reduces milk fat content but also iodide content. Albeit speculative, this may reduce the iodide supply to the newborn calf during the colostral phase and the iodide intake from milk by the consumer.

\section{CONCLUSIONS}

The present study shows for the first time that the NIS gene and iodide uptake is regulated by SREBP in the human mammary epithelial cell line MCF-7. Tran- 
A
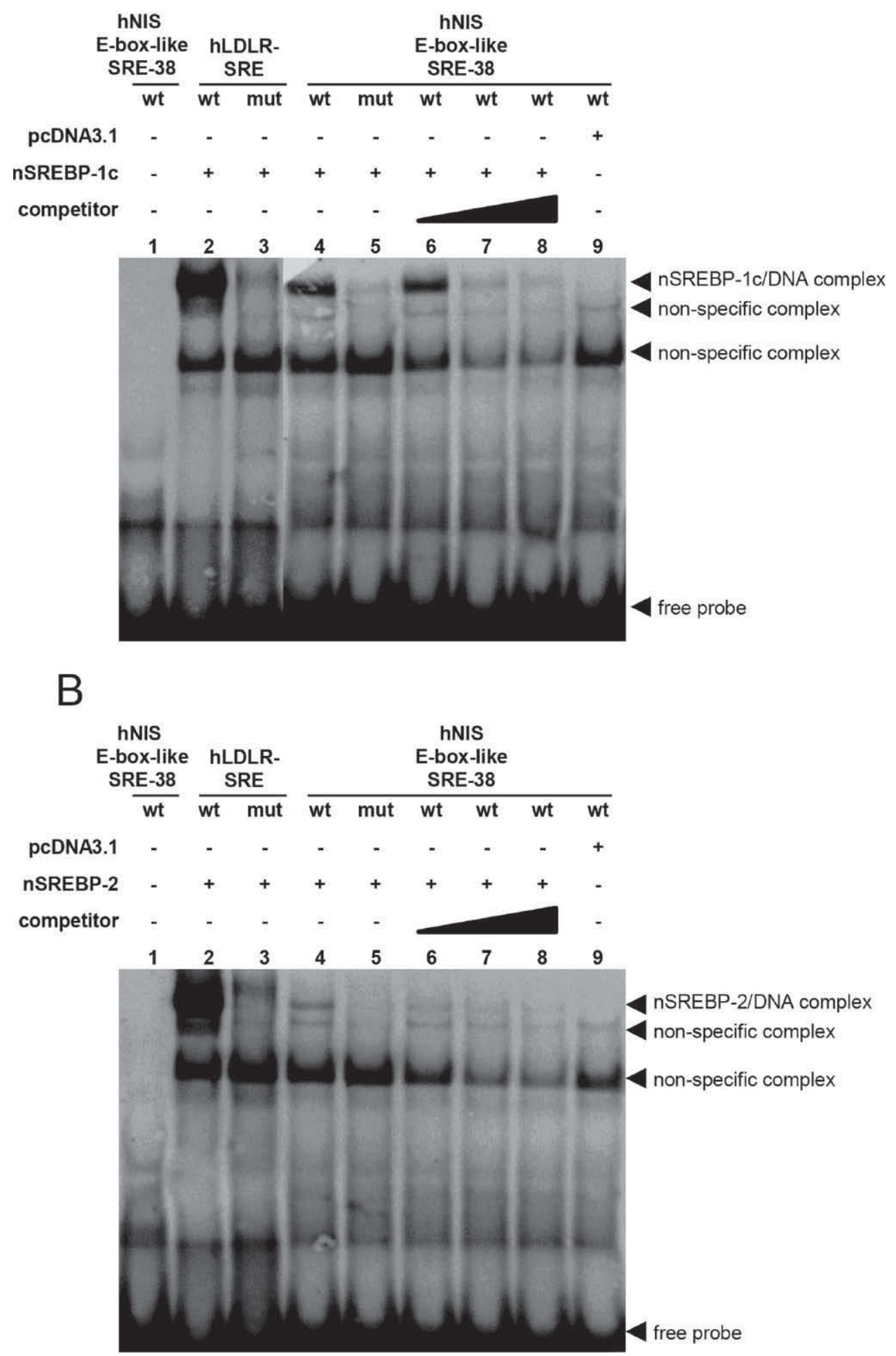

Figure 6. Nuclear sterol regulatory element-binding protein (nSREBP)-1c and nSREBP-2 bind to the E-box-like sterol regulatory element (SRE)-38 of human sodium/iodide symporter $(h N I S)$ 5'-flanking region. Electrophoretic mobility shift assay was performed using in vitro translated nSREBP-1c (A) and nSREBP-2 (B), respectively, and digoxigenin (DIG)-labeled oligonucleotide corresponding to either wild-type (wt) or mutated (mut) E-box-like SRE-38 of hNIS (hNIS E-box-like SRE-38). For competition, 10-, 20-, and 50-fold molar excess of unlabeled specific probe [human low-density lipoprotein receptor (LDLR)-SRE] was used. The DIG-labeled specific probe (hLDLR-SRE) and nonspecific probe (mutated hLDLR-SRE) are also indicated. 
scriptional upregulation of the NIS gene by SREBP is mediated by a functional SREBP binding site located at -38 in the NIS 5 -flanking region, a region that is not essential for thyroid-specific and TSH-dependent NIS gene regulation. This indicates that regulation of the NIS gene by SREBP is primarily important in extra-thyroidal tissues not regulated by TSH, such as the mammary gland. Apart from the important role of SREBP for mammary epithelial cell synthesis of milk lipids, SREBP in the mammary gland of dairy cows and other mammals are involved in the secretion of lipids from mammary epithelial cells into the milk through upregulating various lipid transporters, such as ABCA1, ABCG1, and ABCA7, which are localized in the alveolar cells during lactation and involved in the active efflux of cholesterol, phospholipids, and other lipophilic compounds from the cell. Thereby, SREBP in the lactating mammary gland are critical for maintaining lipid content in the milk and for providing lipophilic nutrients to the calf, at least during the colostral phase. Given that NIS in the lactating mammary gland is responsible for the secretion of iodide into the milk and the supply of the suckling calf during the colostral phase with iodine required for thyroid hormone biosynthesis, the herein identified role of SREBP as regulators of mammary gland NIS indicates that SREBP also play a role in the secretion of nonlipid nutrients and are therefore generally important for maintaining the nutrient content of the milk. According to investigations in rats and mice, NIS is functionally expressed in the alveolar cells during lactation by the cooperative action of the lactogenic hormones oxytocin, prolactin, and estrogens, but the mechanism of NIS gene regulation by these hormones is not completely clear. Thus, future studies have to clarify whether the stimulatory effect of the lactogenic hormones on the NIS gene in the mammary gland may involve the activation of SREBP. Given that the present study has been performed with a human mammary epithelial cell line, future studies have to show that regulation of mammary gland NIS by SREBP is also the case in the lactating bovine mammary epithelium.

\section{REFERENCES}

Alotaibi, H., E. Yaman, D. Salvatore, V. Di Dato, P. Telkoparan, R. Di Lauro, and U. H. Tazebay. 2010. Intronic elements in the Na+/Isymporter gene (NIS) interact with retinoic acid receptors and mediate initiation of transcription. Nucleic Acids Res. 38:3172-3185.

Amemiya-Kudo, M., H. Shimano, A. H. Hasty, N. Yahagi, T. Yoshikawa, T. Matsuzaka, H. Okazaki, Y. Tamura, Y. Iizuka, K. Ohashi, J. Osuga, K. Harada, T. Gotoda, R. Sato, S. Kimura, S. Ishibashi, and N. Yamada. 2002. Transcriptional activities of nuclear SREBP-1a, $-1 \mathrm{c}$, and -2 to different target promoters of lipogenic and cholesterogenic genes. J. Lipid Res. 43:1220-1235.

Barber, M. C., A. J. Vallance, H. T. Kennedy, and M. T. Travers. 2003. Induction of transcripts derived from promoter III of the
acetyl-CoA carboxylase-alpha gene in mammary gland is associated with recruitment of SREBP-1 to a region of the proximal promoter defined by a DNase I hypersensitive site. Biochem. J. 375:489-501.

Bionaz, M., and J. J. Loor. 2008. Gene networks driving bovine milk fat synthesis during the lactation cycle. BMC Genomics 9:366.

Briggs, M. R., C. Yokoyama, X. Wang, M. S. Brown, and J. L. Goldstein. 1993. Nuclear protein that binds sterol regulatory element of low density lipoprotein receptor promoter. I. Identification of the protein and delineation of its target nucleotide sequence. J. Biol. Chem. 268:14490-14496.

Carrasco, N. 1993. Iodide transport in the thyroid gland. Biochim. Biophys. Acta 1154:65-82.

DeBose-Boyd, R. A., J. Ou, J. L. Goldstein, and M. S. Brown. 2001. Expression of sterol regulatory element-binding protein $1 \mathrm{c}$ (SREBP-1c) mRNA in rat hepatoma cells requires endogenous LXR ligands. Proc. Natl. Acad. Sci. USA 98:1477-1482.

Endo, T., M. Kaneshige, M. Nakazato, M. Ohmori, N. Harii, and T. Onaya. 1997. Thyroid transcription factor-1 activates the promoter activity of rat thyroid $\mathrm{Na}^{+} / \mathrm{I}^{-}$symporter gene. Mol. Endocrinol. 11:1747-1755.

Espenshade, P. J., W. P. Li, and D. Yabe. 2002. Sterols block binding of COPII proteins to SCAP, thereby controlling SCAP sorting in ER. Proc. Natl. Acad. Sci. USA 99:11694-11699.

Gessner, D. K., R. Ringseis, M. Siebers, J. Keller, J. Kloster, G. Wen, and K. Eder. 2012. Inhibition of the pro-inflammatory NF- $\kappa B$ pathway by a grape seed and grape marc meal extract in intestinal epithelial cells. J. Anim. Physiol. Anim. Nutr. (Berl.) 96:10741083.

Gill, S., R. Chow, and A. J. Brown. 2008. Sterol regulators of cholesterol homeostasis and beyond: The oxysterol hypothesis revisited and revised. Prog. Lipid Res. 47:391-404.

Harvatine, K. J., and D. E. Bauman. 2006. SREBP1 and thyroid hormone responsive spot 14 (S14) are involved in the regulation of bovine mammary lipid synthesis during diet-induced milk fat depression and treatment with CLA. J. Nutr. 136:2468-2474.

Horton, J. D., J. L. Goldstein, and M. S. Brown. 2002. SREBPs: Activators of the complete program of cholesterol and fatty acid synthesis in the liver. J. Clin. Invest. 109:1125-1131.

Hosseini, A., R. Sharma, M. Bionaz, and J. J. Loor. 2013. Transcriptomics comparisons of Mac-T cells versus mammary tissue during late pregnancy and peak lactation. Adv. Dairy Res. 1:1.

Hua, X., A. Nohturfft, J. L. Goldstein, and M. S. Brown. 1996. Sterol resistance in $\mathrm{CHO}$ cells traced to point mutation in SREBP cleavage-activating protein. Cell 87:415-426.

Hua, X., C. Yokoyama, J. Wu, M. R. Briggs, M. S. Brown, J. L. Goldstein, and X. Wang. 1993. SREBP-2, a second basic-helixloop-helix-leucine zipper protein that stimulates transcription by binding to a sterol regulatory element. Proc. Natl. Acad. Sci. USA 90:11603-11607.

Huynh, H., and M. Pollak. 1995. HH2A, an immortalized bovine mammary epithelial cell line, expresses the gene encoding mammary derived growth inhibitor (MDGI). In Vitro Cell. Dev. Biol. Anim. $31: 25-29$.

Huynh, H. T., G. Robitaille, and J. D. Turner. 1991. Establishment of bovine mammary epithelial cells (MAC-T): An in vitro model for bovine lactation. Exp. Cell Res. 197:191-199.

Inoue, S., K. Yoshinari, M. Sugawara, and Y. Yamazoe. 2011. Activated sterol regulatory element-binding protein-2 suppresses hepatocyte nuclear factor-4-mediated Cyp3a11 expression in mouse liver. Mol. Pharmacol. 79:148-156.

Iwarsson, K. 1973. Rapeseed meal as a protein supplement for dairy cows. I. The influence on certain blood and milk parameters. Acta Vet. Scand. 14:570-594.

Kogai, T., J. J. Schultz, L. S. Johnson, M. Huang, and G. A. Brent. 2000. Retinoic acid induces sodium/iodide symporter gene expression and radioiodide uptake in the MCF-7 breast cancer cell line. Proc. Natl. Acad. Sci. USA 97:8519-8524.

Laglia, G., M. A. Zeiger, A. Leipricht, P. Caturegli, M. A. Levine, L. D. Kohn, and M. Saji. 1996. Increased cyclic adenosine $3{ }^{\prime}, 5^{\prime}$-mono- 
phosphate inhibits $\mathrm{G}$ protein-coupled activation of phospholipase C in rat FRTL-5 thyroid cells. Endocrinology 137:3170-3176.

Levy, O., G. Dai, C. Riedel, C. S. Ginter, E. M. Paul, A. N. Lebowitz, and N. Carrasco. 1997. Characterization of the thyroid Na+ I- symporter with an anti-COOH terminus antibody. Proc. Natl. Acad. Sci. USA 94:5568-5573.

Li, X., P. Hylemon, W. M. Pandak, and S. Ren. 2006. Enzyme activity assay for cholesterol 27-hydroxylase in mitochondria. J. Lipid Res. 47:1507-1512.

Li, X., W. M. Pandak, S. K. Erickson, Y. Ma, L. Yin, P. Hylemon, and S. Ren. 2007. Biosynthesis of the regulatory oxysterol, 5-cholesten3beta,25-diol 3-sulfate, in hepatocytes. J. Lipid Res. 48:2587-2596.

Lock, A. L., M. Rovai, T. A. Gipson, M. J. de Veth, and D. E. Bauman. 2008. A conjugated linoleic acid supplement containing trans-10, cis-12 conjugated linoleic acid reduces milk fat synthesis in lactating goats. J. Dairy Sci. 91:3291-3299.

Lock, A. L., B. M. Teles, J. W. Perfield 2nd, D. E. Bauman, and L. A. Sinclair. 2006. A conjugated linoleic acid supplement containing trans-10, cis-12 reduces milk fat synthesis in lactating sheep. J. Dairy Sci. 89:1525-1532.

Loor, J. J., and J. H. Herbein. 1998. Exogenous conjugated linoleic acid isomers reduce bovine milk fat concentration and yield by inhibiting de novo fatty acid synthesis. J. Nutr. 128:2411-2419.

Ma, Y., L. Xu, D. Rodriguez-Agudo, X. Li, D. M. Heuman, P. B Hylemon, W. M. Pandak, and S. Ren. 2008. 25-Hydroxycholesterol-3-sulfate regulates macrophage lipid metabolism via the LXR/ SREBP-1 signaling pathway. Am. J. Physiol. Endocrinol. Metab. 295:E1369-E1379.

Mani, O., M. Körner, M. T. Sorensen, K. Sejrsen, C. Wotzkow, C. E. Ontsouka, R. R. Friis, R. M. Bruckmaier, and C. Albrecht. 2010 Expression, localization, and functional model of cholesterol transporters in lactating and nonlactating mammary tissues of murine, bovine, and human origin. Am. J. Physiol. Regul. Integr. Comp. Physiol. 299:R642-R654.

Nara, T. Y., W. S. He, C. Tang, S. D. Clarke, and M. T. Nakamura. 2002. The E-box like sterol regulatory element mediates the suppression of human Delta-6 desaturase gene by highly unsaturated fatty acids. Biochem. Biophys. Res. Commun. 296:111-117.

Nicola, J. P., M. Nazar, I. D. Mascanfroni, C.-G. Pellizas, and A. M.

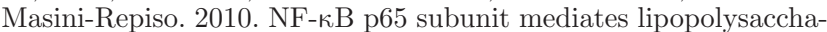
ride-induced $\mathrm{Na}(+) / \mathrm{I}(-)$ symporter gene expression by involving functional interaction with the paired domain transcription factor Pax8. Mol. Endocrinol. 24:1846-1862.

Nohturfft, A., D. Yabe, J. L. Goldstein, M. S. Brown, and P. J. Espenshade. 2000. Regulated step in cholesterol feedback localized to budding of SCAP from ER membranes. Cell 102:315-323.

Osborne, T. F., and P. J. Espenshade. 2009. Evolutionary conservation and adaptation in the mechanism that regulates SREBP action: What a long, strange tRIP it's been. Genes Dev. 23:2578-2591.

Papas, A., J. R. Ingalls, and L. D. Campbell. 1979. Studies on the effects of rapeseed meal on thyroid status of cattle, glucosinolate and iodine content of milk and other parameters. J. Nutr. 109:1129-1139.

Perfield, J. W. 2nd, A. L. Lock, J. M. Griinari, A. Saebø, P. Delmonte, D. A. Dwyer, and D. E. Bauman. 2007. Trans-9, cis-11 conjugated linoleic acid reduces milk fat synthesis in lactating dairy cows. J. Dairy Sci. 90:2211-2218.

Peterson, D. G., E. A. Matitashvili, and D. E. Bauman. 2004. The inhibitory effect of trans-10, cis-12 CLA on lipid synthesis in bovine mammary epithelial cells involves reduced proteolytic activation of the transcription factor SREBP-1. J. Nutr. 134:2523-2527.

Piironen, E., and A. I. Virtanen. 1963. The effect of thiocyanate in nutrition on the iodine content of cow's milk. Z. Ernahrungswiss. 3:140-147.

Ren, S., P. Hylemon, Z. P. Zhang, D. Rodriguez-Agudo, D. Marques, X. Li, H. Zhou, G. Gil, and W. M. Pandak. 2006. Identification of a novel sulfonated oxysterol, 5-cholesten-3beta,25-diol 3-sulfonate, in hepatocyte nuclei and mitochondria. J. Lipid Res. 47:1081-1090.
Rillema, J. A., T. X. Yu, and S. M. Jhiang. 2000. Effect of prolactin on sodium iodide symporter expression in mouse mammary gland explants. Am. J. Physiol. Endocrinol. Metab. 279:E769-E772.

Ringseis, R., C. Rauer, S. Rothe, D. K. Gessner, L. M. Schütz, S. Luci, G. Wen, and K. Eder. 2013. Sterol regulatory element-binding proteins are regulators of the NIS gene in thyroid cells. Mol. Endocrinol. 27:781-800.

Ringseis, R., D. Saal, A. Müller, H. Steinhart, and K. Eder. 2004. Dietary conjugated linoleic acids lower the triacylglycerol concentration in the milk of lactating rats and impair the growth and increase the mortality of their suckling pups. J. Nutr. 134:3327-3334.

Rudolph, M. C., J. L. McManaman, T. Phang, T. Russell, D. J. Kominsky, N. J. Serkova, T. Stein, S. M. Anderson, and M. C. Neville. 2007. Metabolic regulation in the lactating mammary gland: A lipid synthesizing machine. Physiol. Genomics 28:323-336.

Rudolph, M. C., J. Monks, V. Burns, M. Phistry, R. Marians, M. R. Foote, D. E. Bauman, S. M. Anderson, and M. C. Neville. 2010 Sterol regulatory element binding protein and dietary lipid regulation of fatty acid synthesis in the mammary epithelium. Am. J. Physiol. Endocrinol. Metab. 299:E918-E927.

Sato, R. 2010. Sterol metabolism and SREBP activation. Arch. Biochem. Biophys. 501:177-181.

Schmid, E., W. W. Franke, C. Grund, D. L. Schiller, H. Kolb, and N. Paweletz. 1983. An epithelial cell line with elongated myoid morphology derived from bovine mammary gland. Expression of cytokeratins and desmosomal plaque proteins in unusual arrays. Exp. Cell Res. 146:309-328.

Soule, H. D., J. Vazguez, A. Long, S. Albert, and M. Brennan. 1973. A human cell line from a pleural effusion derived from a breast carcinoma. J. Natl. Cancer Inst. 51:1409-1416.

Tazebay, U. H., I. L. Wapnir, O. Levy, O. Dohan, L. S. Zuckier, Q. H. Zhao, H. F. Deng, P. S. Amenta, S. Fineberg, R. G. Pestell, and N. Carrasco. 2000. The mammary gland iodide transporter is expressed during lactation and in breast cancer. Nat. Med. 6:871-878

Tsunoda, T., and T. Takagi. 1999. Estimating transcription factor bindability on DNA. Bioinformatics 15:622-630.

Vassart, G., and J. E. Dumont. 1992. The thyrotropin receptor and the regulation of thyrocyte function and growth. Endocr. Rev. 13:596-611.

Wen, G., R. Ringseis, and K. Eder. 2010. Mouse OCTN2 is directly regulated by peroxisome proliferator-activated receptor $\alpha$ $(\operatorname{PPAR} \alpha)$ via a PPRE located in the first intron. Biochem. Pharmacol. 79:768-776.

Wingender, E., X. Chen, E. Fricke, R. Geffers, R. Hehl, I. Liebich, M. Krull, V. Matys, H. Michael, R. Ohnhäuser, M. Prüss, F. Schacherer, S. Thiele, and S. Urbach. 2001. The TRANSFAC system on gene expression regulation. Nucleic Acids Res. 29:281-283.

Yang, T., P. J. Espenshade, M. E. Wright, D. Yabe, Y. Gong, R Aebersold, J. L. Goldstein, and M. S. Brown. 2002. Crucial step in cholesterol homeostasis: Sterols promote binding of SCAP to INSIG-1, a membrane protein that facilitates retention of SREBPs in ER. Cell 110:489-500.

Yokovama, C., X. Wang, M. R. Briggs, A. Admon, J. Wu, X. Hua, J. L. Goldstein, and M. S. Brown. 1993. SREBP-1, a basic-helixloop-helix-leucine zipper protein that controls transcription of the low density lipoprotein receptor gene. Cell 75:187-197.

Yoshida, A., N. Sasaki, A. Mori, S. Taniguchi, Y. Ueta, K. Hattori, Y. Tanaka, O. Igawa, M. Tsuboi, H. Sugawa, R. Sato, I. Hisatome, C. Shigemasa, E. F. Grollman, and S. Kosugi. 1998. Differences in the electrophysiological response to I- and the inhibitory anions SCN- and ClO-4, studied in FRTL-5 cells. Biochim. Biophys. Acta 1414:231-237.

Zavizion, B., M. van Duffelen, W. Schaeffer, and I. Politis. 1996. Establishment and characterization of a bovine mammary epithelial cell line with unique properties. In Vitro Cell. Dev. Biol. Anim. $32: 138-148$ 